\title{
Education Research in Australia: Where is it Conducted?
}

\section{Janette Bobis}

Faculty of Education and Social Work, The University of Sydney

\section{Sue Shore}

School of Education, Charles Darwin University

\section{Dawn Bennett}

Humanities Research and Graduate Studies, Curtin University

Sue Bennett

Faculty of Education, University of Wollongong

\section{Phillip Chan}

Faculty of Education, Monash University

\section{Neil Harrison}

School of Education, Macquarie University

\section{Terri Seddon}

Faculty of Education, Monash University

\section{Corresponding author:}

\section{Janette Bobis}

Associate Professor Mathematics Education

Faculty of Education and Social Work

The University of Sydney

Rm 333 Education Building, A35 | The University of Sydney | NSW | 2006

$\mathrm{T}+61293514536 \mid \mathrm{F}+61293512606$

E janette.bobis@sydney.edu.au 


\title{
Education Research in Australia: Where is it Conducted?
}

\begin{abstract}
Research assessment exercises aim to identify research quantity and quality and provide insights into research capacity building strategies for the future. Yet with limited knowledge of the ecology of Australian educational research, there is little chance of understanding what research audits might contribute towards a capacity building agenda for such a complex field. This paper draws on secondary data analysis of research outputs submitted by 13 Australian higher education institutions to the Excellence in Research for Australia (ERA) 2010 and 2012 national research assessment exercises, to show where Australian educational research is conducted. Findings offer a profile of education researchers by location in academic organisational units within universities. By analyzing data not accessible through reported ERA data we were also able to present information about appointment profiles, specifically levels and type of appointment within universities, as well as data on institutional and geographic region, and patterns associated with type of outputs (books, book chapters, journal articles, conference papers and other outputs) and field of research. Analysis of the data reveals definitive shifts in the nature of the published outputs and in employment profiles of researchers and their location across university and regional groupings. Research audits are administrative processes that reshape institutional and disciplinary governance structures, policies, individual outputs, work practices and careers, but they are not the sum total of the field per se.
\end{abstract}

\section{Keywords}

audit culture, educational research, ERA, research metrics, research assessment, 


\section{Education Research in Australia: Where is it Conducted?}

\section{Introduction}

This paper addresses a ubiquitous topic of debate in higher education policy: the use of performance metrics - external research funding, citations, journal impact factor, tiered journal rankings and graduate completions amongst other things - as indicators of university quality, research quality and researcher quality. The research-steering practices that guide policy work on this issue have grown out of a conglomerate of assessment activities and supra- and trans-national agency activity (cf Alexiadou and Jones cited in Ozga, Seddon and Popkewitz 2006) as diverse as the World Bank, the Organisation for Economic Cooperation and Development (OECD) and national research agency priorities such as those developed by the Australian Research Council (ARC). As 'travelling policies' (ibid), the effects of such practices steer national decisions about higher education research management and epistemological governance of the research community (Hardy, Heimans and Lingard 2011; Larkins 2013a, 2013b; Lawn and Furlong 2007;). However the influence of audits on management and epistemological governance are difficult to track because of complex formulae (cf Hicks 2012) interpreted at local levels within institutions with competitive histories of disciplinary funding.

This is a very complex space indeed. Research-steering practices not only define and prioritise the measures for research performance, but actively constitute the people, their outputs, their networks, their sanctioned (and unendorsed or 'other') research activity and so also their research subjectivities and careers (Connell 2007; Gardner and Gallagher 2007; Hardy et al. 2011; Rizvi 2009). Moreover, within this space there is the ever-present rub up against 'soft capitalism' and its demand for 'hypersurveillance' of constant productivity (Thrift 2005). In all of this, the categories constituted by transnational, national, regional and local audits are not replacements for the discipline, the profession, the research activity, or the researcher. In this paper we reference the 'epistemological' entity (Hardy et al. 2011) - the discipline of educational research - as something shaped through a long history of funding, recruitment and scholarly practices between universities and education systems. The 'auditable entity' education research (henceforth referred to as FoR Education) is a 
product of recently introduced Australian research performance audits and the classification systems use by the national statistics agency - the Australian Bureau of Statistics (ABS). We maintain the tension between the two to illustrate the extent to which audits have induced changes in the character of higher education institutions and paradoxically shaped the enterprising conditions which are so contested by higher education employers and employees today (cf Kwok 2013; Marginson 2002).

In this paper we draw attention to a range of critical issues that have shaped educational research during a time of substantive change in university research management. Using secondary analysis of data from 13 participating universities we explore the research ecologies of educational research through a key research question: What might we learn of the topography of educational research from the two recent audits of Australian university research? This may illuminate the tensions between practices that constitute the 'auditable entity' FoR Education and the 'epistemological entity' educational research and so also the research capacity building activities required for the future.

\section{Research steering practices and educational research}

The impetus for this paper was prompted by results of the first Excellence in Research for Australia (ERA) (ARC 2011). At the time in Australia educational researchers worked across a range of sites in Australian universities and were a diverse group. Indeed, citing Australian Research Council figures, the Australian Council of Deans of Education [ACDE] (2009) argue education is a discipline that punches above its weight:

Australia produces $5.4 \%$ of all the educational research publications created around the world - almost double the proportion of research publications produced by Australia generally (around 2.9\%). This places Education first in all Fields of Research in Australia followed by Plant and Animal Sciences $(5.30 \%)$ and Geosciences $(5.02 \%)$.

However ERA 2010 also revealed "we had no up-to-date picture of who is involved in educational research, what their strengths are, or how they relate to one another" (Seddon, Bennett, Bobis, Bennett, Harrison, Shore, Smith and Chan 2013 p. 1). Even more disconcerting, and in contrast to the argument that we might be punching above 
our weight, was the observation that "the national average weighting of Australian educational research was well below the "world standard' rating of 3.0" (ibid). Educational researchers in other countries were similarly engaged with these steering practices and noting a number of common concerns (Besley 2009; Furlong 2011; Hicks 2012; Jansen and Watts 2011; Ozga et al. 2006) which we situate here in the context of Australian educational research.

Educational research capacity building is inevitably caught up in its history in the academy (cf Furlong 2011), and in Australia our lineage with teacher training colleges is an important part of educational research capacity building. Some of the key moves relevant to this issue are the first division of universities and teachers' colleges mandated by Menzies in 1958 (cf Bebbington 2012 p. 74); the Dawkins restructuring of education producing a "unified national system emerging in the late 1980s and early 1990s"; and the more recent reshaping of that system as higher education and VET in the late 2000s (O'Neill and Speechley 2011 p. 97). These structural changes travelled with more subtle recruitment, disciplinary and funding practices that shaped the who, what, how and where of education research, researchers and research outcomes (cf Cooper and Poletti 2011; Ryan 2012), balancing all the while the tensions between massification, marketization, corporatisation and latterly "increased managerialism, greater efficiencies, compliance, quality and research measurements" (Ryan 2012 p. 5). These articulations between the economy and academic work reshaped research governance and how researchers experienced their labour. They also shaped the ongoing condescension towards Education as a discipline, the recurring view that educational research lacks disciplinary depth and rigour, and educational researcher responses to these views (Furlong 2011).

The notion of audit embedded in ERA and other research assessment exercises is premised on assumptions of the neutrality of academic criteria such as "originality, significance and rigour" (Rizvi 2009 p. 51) and a notion of 'world standard research' (ARC 2011) in which 'the world' and its international dimensions are also presented as neutral spaces of knowledge production (Rizvi 2009). The following discussion situates the constitution of 'excellence' and 'world standard' in the context of the audited lives of contemporary academics and the disciplinary features of neoliberal managerialism that underpin modern university governance frameworks (Cooper, 
Hinkson and Sharp 2002; Cooper and Poletti 2011). These and other authors (Connell 2007; Hicks 2012; Rizvi 2009) argue that exercises such as the UK Research Assessment Exercise (RAE), the New Zealand Performance Based Research Fund (PBRF) and the Australian ERA (as well as their future iterations) draw on hierarchies of othering, racialised and gendered knowledge practices, and intellectual practices centred around metro-centric geographies of knowledge production. This approach to research assessment is premised on "black boxing [that] hides the human decisions and complex technological work that is involved in producing objectivity" (Hardy et al. 2011 p. 6, after Rose 1999).

Many of these decisions to produce objectivity focus on more publications and citations in higher ranked journals despite the profound changes in publishing practices around the world: journal rankings are no longer formally used in the Australian audits; publishing houses increasingly promote standalone book chapters in e-book publications; blogs and wikis and websites are replacing more traditional research outputs to reach diverse audiences; and circumvent restrictive copyright and publishing regimes and so on. When these changes in the academic publishing industry are combined with the Anglocentric language restrictions on 'world standard' knowledge circulation, the ethical and epistemological assumptions accompanying the white public space of the academy, the dubious neutrality of academic reviewers and the complicated relations between academics, publishing houses and marketization of research, the actual measurement of international excellence (Rizvi 2009) remains unclear.

The challenges are even more demanding in the light of fragmenting practices of managerialist cultures in contemporary universities - "numbers, grids, performance indicators and rankings" (Hardy et al. 2011 p. 6) that promote distrust and social distance in cultures that once involved substantial collective deliberation. One must be careful though, to not over-romanticise the past and valorise a pan-university culture that glosses the gendered and racialised divisions of the elite university collegiality of the past. Nevertheless these practices take on new contours, as they become part of the cultural regime of 'soft capitalism' and its valorisation of constant productivity and constant appropriation of other knowledges (Connell 2012; Rizvi 2009; Thrift 2005). These insights have particular relevance for research capacity 
building if one understands the rub up between 'world standard' assessments, and international and regional knowledge practices. With these issues in mind our goal was to explore topographical features of FoR Education under construction through research knowledge production practices (ABS 2012; ERA 2011, 2012) as we also considered what these audit practices might contribute to educational research capacity building.

\section{An Australian response: Introducing ERA}

ERA is an initiative intended to assess the quality and quantity of research across all disciplines and higher education institutions in Australia. Using a combination of metrics (e.g. citations) and expert review, outputs are assessed according to established Fields of Research (FoR) (ABS, 2012). Twenty-two 2-digit and 157 4digit field of research codes are used to classify and rate on a 5-point scale (from 1 well below world standard, to 5 - well above world standard) all outputs submitted for assessment. For instance, FoR 13 Education (henceforth referred to as FoR Education) has four 4-digit FoR codes: 1301 Education Systems; 1302 Curriculum and Pedagogy; 1303 Specialist Studies in Education; and 1399 Other Education.

Universities are required by the Australian Government to submit data to each ERA exercise. To date there have been two ERAs, the first occurring in 2010 and the second in 2012. The ERA 2010 assessment period included research outputs from 2003 to 2008 inclusive. Institutions were required to submit a $20 \%$ representative sample of outputs from each category (e.g. $20 \%$ each of books, book chapters etc) in each 4-digit FoR. The ERA 2012 assessment period included outputs from 2005 to 2010 inclusive and required a 30\% representative sample of outputs. While there was an overlap of four years in each assessment period, the outputs that were submitted for ERA 2010 may not have been selected for assessment in 2012. These data provided a snapshot profile of educational research in Australia, which was used to assess its excellence in relation to world standard.

The impetus for this paper was prompted by concerns to explore where educational research is conducted as evidenced by the outputs submitted to ERA 2010 and 2012, and simultaneously to build a better understanding of the ecology of Australian educational research. Our perspective of 'where' was not restricted to the physical 
geographical location of universities or of academic units with in universities. We also examined 'where' in terms of both the employment profiles of academics producing the outputs and 'where' the outputs were categorised - their publication type and FoR at the 2-digit level.

\section{Methodology}

In the UK, data from the RAE were publicly available to researchers in all discipline fields and were used extensively to better understand research and to inform strategic research capacity building across the university sector (e.g. Lawn and Furlong 2007). In Australia, however, ERA data were not made available for secondary analysis by the higher education sector.

\section{Data Collection Instruments and Procedures}

We approached forty-two Higher Education Institutions, comprising 39 universities and three other colleges/institutes that submitted data to ERA 2010 and 2012. Participant information was sent to all Deans of Education and Vice Chancellors of Research or their counterparts informing them of the project and asking for their approval and cooperation. Invitation emails were then sent to a nominated coordinator associated with education research in each institution.

To ensure consistency of data collection and to minimise additional workload on administration staff, data templates were created using Microsoft ${ }^{\circledR}$ Excel. The templates were constructed to align closely with data already compiled for recent ERA 2010 and 2012 submissions. Institutions were asked to import their ERA data into the templates and in the process replace researcher identifiers with an alias to ensure their anonymity.

The data were collated using Microsoft ${ }^{\circledR}$ Excel and checked for accuracy by the research team. Double entries of outputs or researchers were removed and all fields of research codes were checked to ensure that outputs and researchers were correctly attributed to Education or another FoR. Fifteen universities returned their ERA data. Data from two institutions could not be used due to incomplete data sets being submitted. The 13 useable data sets included representation from all designated 
university groupings except the Australian Technology Network (see www.australianuniversities.com.au/ for a full list of university groupings).

Before agreeing to participate, some institutions sought further reassurance that anonymity of institution and ERA data would be maintained, including in subsequent reports and other publications. Others expressed a commitment to submit data but were unable to comply because of workload demands on research administrative staff. Yet other institutions responded that despite the existence of an approved ethics protocol, they had reservations about project capacity to maintain anonymity of data. As a result of these concerns the research team used three regional categories Southeast, East and West/Northeast/Central - to discuss geographical origins of outputs and researchers. These broad regional categories were intentionally selected to allay institutional concerns about anonymity.

\section{Results and Discussion}

In reviewing the literature it was evident that universities nationally and internationally had experienced major structural change. This contributed substantially to the ambiguity around how 'education' was represented internally and as an institutional entity across Australian universities, as well as presenting problems for analysis of the data. The notion of an 'academic organisational unit' (AOU) therefore became central to our analysis and discussion of results.

The outcomes of ERA 2010 suggested that educational knowledge building occurred in many institutional locations beyond Education AOUs. As a starting point this study mapped these different locations by cross-tabulating ERA data for 2010 and 2012 by AOU. This procedure generated three categories of education-related research outputs:

Category 1: Outputs produced in Education AOUs and submitted to FoR Education;

Category 2: Outputs produced in Education AOUs and submitted to other FoR codes; and

Category 3: Outputs produced in non-Education AOUs and submitted to FoR Education. 
A researcher who works in an Education AOU may have research outputs coded in multiple ways - some outputs may be coded solely using FoR Education codes while other outputs may be coded partly or entirely in, or across, one, two or three other FoRs. The above categories assisted us to answer key questions about the 'where' of Australian educational research production. This covered distribution questions such as where according to academic organisational unit; where according to types of outputs; where according to FoR of outputs; where according to academic level and appointment type; and, where according to geographic region and national university groupings. This framework highlighted previously unreported aspects of Australian educational research, including where educational researchers who do not work in Education AOUs come from and articulations with appointment levels.

\section{Outputs by academic organisational unit}

Table 1 shows the number of outputs submitted to FoR Education for ERA 2010 and ERA 2012 by the 13 Universities participating in this study. It highlights the percentage share of outputs by academics working in Education AOUs (Category 1) and other AOUs (Category 3). The data are presented in this way because of the different 'representative sample' requirements for outputs across the two ERA exercises (20\% for ERA 2010 and 30\% for ERA 2012). Hence it is more meaningful to compare percentage shares rather than actual numbers of outputs.

Table 1. Comparison of ERA 2010 and ERA 2012 share of outputs submitted to FoR Education 


\begin{tabular}{lccc}
\hline & $\begin{array}{c}\mathbf{2 0 1 0} \\
(\boldsymbol{n}=7,831 \\
\text { outputs })\end{array}$ & $\begin{array}{c}\mathbf{2 0 1 2} \\
(\boldsymbol{n}=9,956 \\
\text { outputs })\end{array}$ & $\begin{array}{c}\text { Percentage } \\
\text { points } \\
\text { difference }\end{array}$ \\
\hline $\begin{array}{l}\text { Category 1: Research } \\
\text { outputs produced in an } \\
\text { Education AOU }\end{array}$ & $54.8 \%$ & $59.3 \%$ & +4.5 \\
\hline $\begin{array}{l}\text { Category 3: Research } \\
\text { outputs produced in a } \\
\text { non-Education AOU }\end{array}$ & $40.3 \%$ & $37.4 \%$ & -2.9 \\
\hline $\begin{array}{l}\text { Outputs from } \\
\text { researchers whose } \\
\text { AOU was } \\
\text { unidentifiable }\end{array}$ & $4.9 \%$ & $3.3 \%$ & -1.6 \\
\hline
\end{tabular}

As shown in Table 1, a little over half (54.8\%) of the research outputs submitted to FoR Education for ERA 2010 were produced in Education AOUs. However, this increased by 4.5 percentage points to $59.3 \%$ of outputs for the ERA 2012 submission with an accompanying decrease in the percentage contribution from non-Education AOUs. Given the overlap of four years (2005 to 2008) in the two assessment periods, it is unlikely that the increase could be produced wholly within Education AOUs within the space of the two-year overlap period - 2009 to 2010.

ERA 2012 gave institutions and AOUs greater flexibility in assigning multiple codes to interdisciplinary journal articles, albeit conditional on two-thirds of the article's content aligning with the newly assigned code. As other commentators have argued (Larkins 2013b), the added flexibility in coding, particularly of journal articles, provided AOUs and institutions more options to strengthen their submissions. In addition to added coding flexibility, many journals have pre-determined codes in more than one FoR. Academics could select the single most appropriate FoR or spread credit across more than one FoR: for example an article published in The Journal of Educational Psychology could be coded wholly in FoR 1303 Special Studies in Education, in FoR 1701 Psychology, in FoR 1702 Cognitive Science or be shared between two or all three FoRs. Moreover, procedural changes to ERA 2012 facilitated greater institutional autonomy regarding the way outputs could be coded. A similar approach to the coding of other outputs (books, book chapters etc.) that rely on the discretion of institutions for appropriate coding, would result in more Category 
1 outputs in an FoR Education submission. The second research assessment round saw many Education AOUs go to greater lengths to ensure not only that outputs were coded wholly in (or out of) a FoR targeted for strengthening within an institution, but also the AOU location they wanted to direct the resultant allocation of research funds (Kwok 2013).

\section{Non-Education AOUs that submit outputs to FoR Education}

Despite the increase in outputs from Education AOUs noted above, a significant share of FoR Education outputs in both assessment exercises came from nonEducation AOUs. However, a number of factors hampered efforts to determine the non-Education AOU location of outputs submitted to both ERA exercises. Foremost was the fact that nearly every university in the sample underwent some form of restructuring during the two assessment periods. Various AOU names appeared and disappeared between, and even within, assessment periods. These changes made it impossible to compile a definitive list of AOUs to compare output contributions for each audit. Instead we used broad discipline categories to organise the AOU origin of outputs. We focus here only on ERA 2012 data to identify the non-Education AOU outputs given that this data reflects the most recent status of AOUs.

The AOUs associated with Category 3 (non-Education AOU) outputs were extremely diverse. Of the 13 universities who participated in this study, there was only one institution whose total FoR Education outputs were produced solely by academics working in Education AOUs. In contrast, 70\% of the Education outputs at another institution were Category 3. The proportion of Category 3 outputs at the remaining 11 institutions, fell somewhere between these two extremes. The mean number of Category 3 outputs across all the institutions in the ERA 2012 data set was $38.7 \%$. These outputs predominantly came from researchers working in the health and medical related disciplines, accounting for $28 \%$ of the FoR Education outputs in 2012. Notable contributions also originated from researchers located in the disciplines of arts, science and business in 12 of the 13 universities.

While information from the ERA 2010 or ERA 2012 national reports (ARC 2011; 2012) and an Australian Council of Deans of Education [ACDE] workforce report (Cummings 2010) made it clear that researchers working in non-Education academic 
organisational units also contributed to FoR Education, they did not give any indication of the depth or breadth of their contributions. Previous studies (e.g. Lawn and Furlong 2007) have confirmed the complexity of Education as a field of study and research, but what is particularly interesting about this Australian data is the overall high proportion of outputs originating from non-Education AOUs. An OECD study cited by Lawn and Furlong (2007 p. 15) "concluded that approximately $90 \%$ of education research was undertaken by lecturers and research staff employed in university departments of education". Reasons for the huge disparity between the number of English and Australian outputs outside education are not clear. However, we are able to use current data to find out more about the nature of both Category 1 and Category 3 outputs and the researchers who produce them.

\section{Academic level and appointment type of researchers who submit outputs to FoR}

\section{Education}

The ERA 2010 National Report (ARC 2011) provided information relating to academic level, but it did not provide important information concerning type of appointment. Our secondary analysis of data included requests for academic level and appointment type for researchers submitting outputs to FoR Education. Figures 1 and 2 show the number of researchers who submitted Category 1 (Education AOU) and Category 3 (non-Education AOU) outputs along with their academic level (Level A-E or 'other', including honoraries and those whose level information was missing) and appointment type (research only, teaching only, teaching and research).

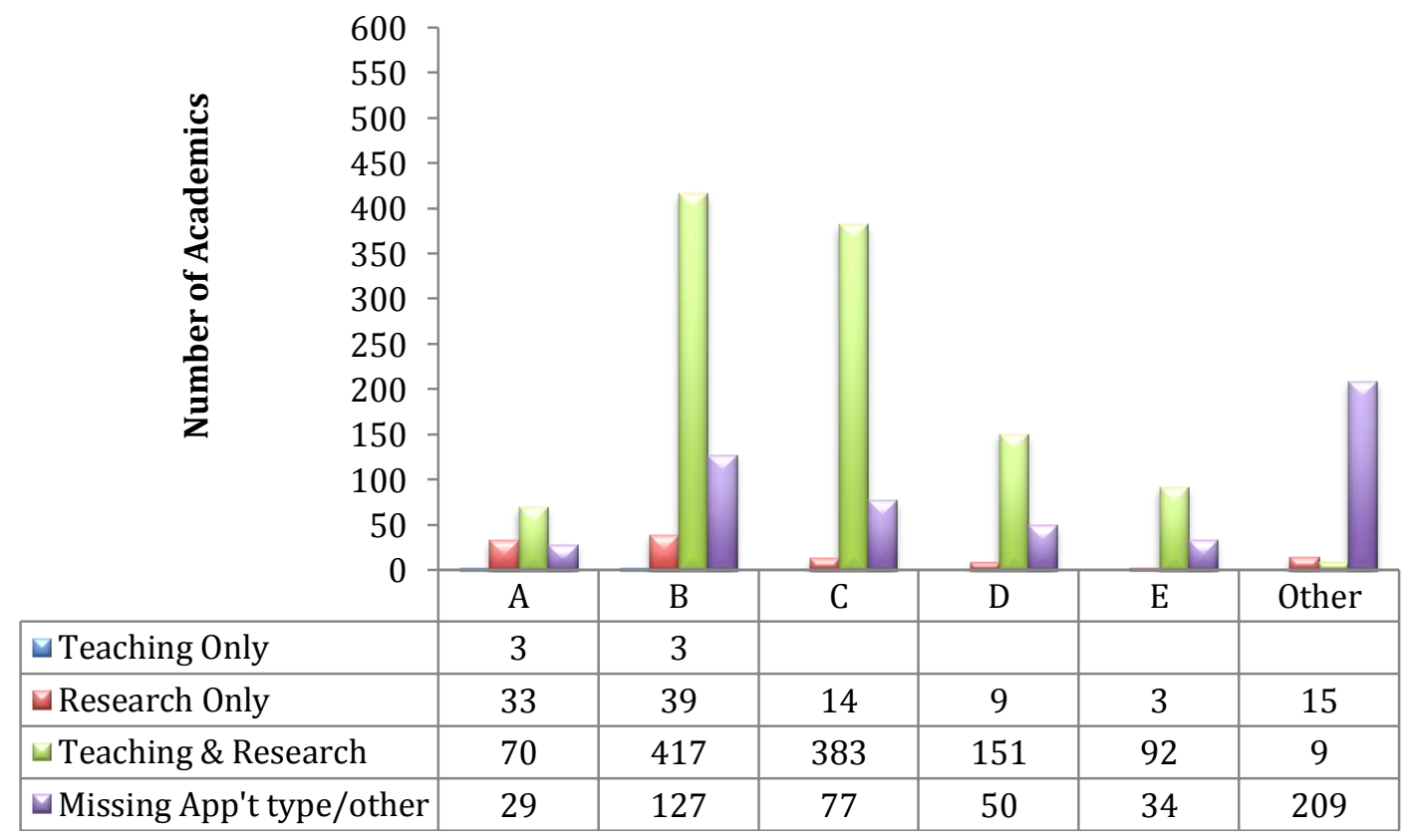


Fig. 1. Appointment level and type of ERA 2010 researchers contributing to the FoR Education submission

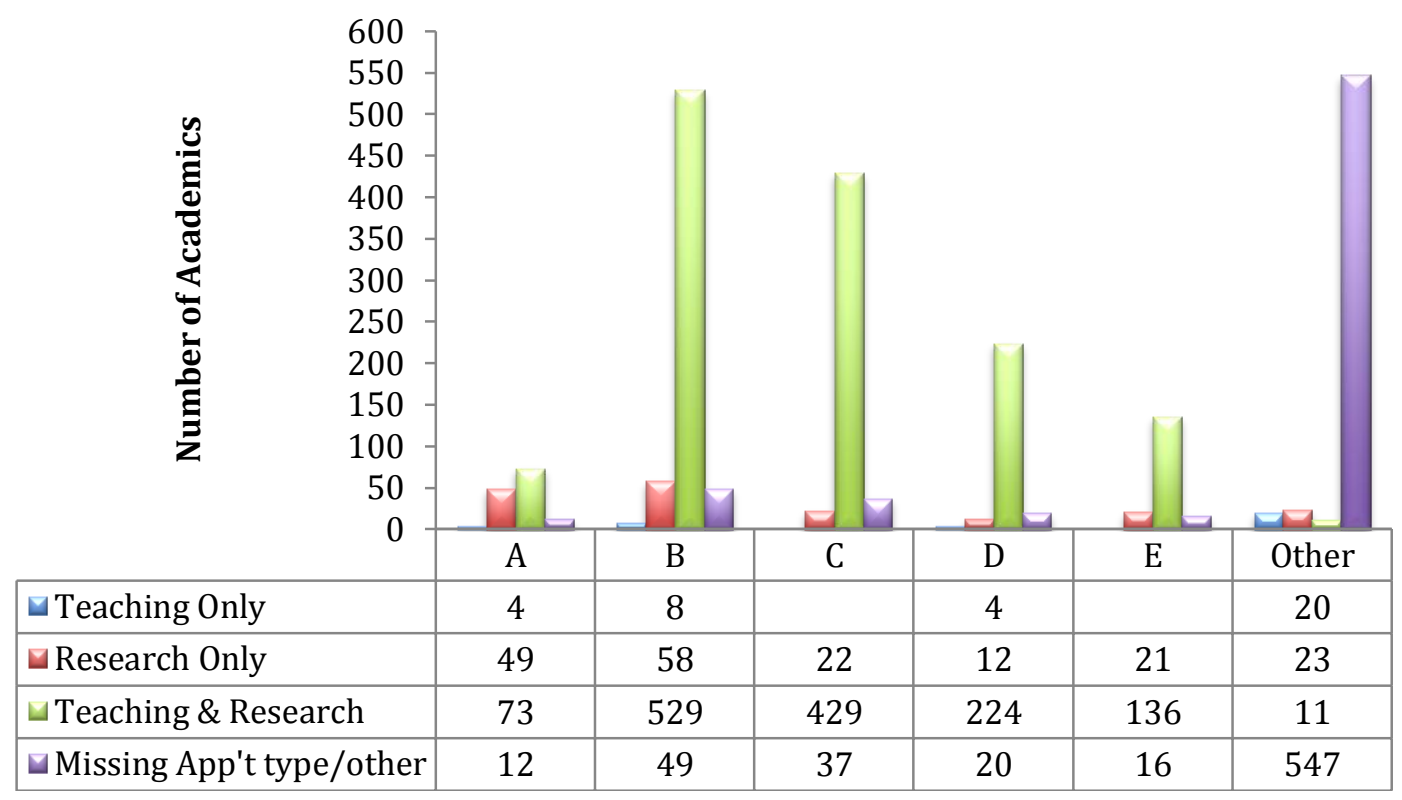

Fig. 2. Appointment type and level of ERA 2012 researchers contributing to the FoR Education submission

The number of teaching only appointments was quite small in both assessment periods. Our review of related literature indicated a mixed pattern of teaching only appointments within universities and in Schools of Education, related in part to the professional career pathways of education academics (Aspromougos 2012). The slight increase in the number of teaching appointments for ERA 2012 may be indicative of a changing trend in appointment types based on a number of factors including recent changes to the Collective Agreements between higher education employers and employees (http://www.nteu.org.au/rights/conditions/agreements), institutional economic circumstances and institutional decisions about research and teaching foci.

The increase in teaching focused appointments, coupled with the larger number of Level $\mathrm{B}$ and $\mathrm{C}$ academics in teaching and research appointments, highlights the intimate relationship between teaching and research for FoR Educational researchers. This is further affirmed by the relatively small number of FoR Education academics with research only appointments in both assessment periods and by Cummings's 
(2010) cross-disciplinary report to the ACDE, which noted low numbers of research only academics in Education (matched only by similar numbers in the discipline of Management and Commerce). Our secondary analysis reveals that the majority of the research only academics are Level A and B, suggesting a profile that reflects early career research or post doctorate appointments rather than research only Professorial appointments.

There is also a slight increase from 2010 to 2012 in the number of Professorial research appointments. Consistent with other observations this may be a result of universities either 'buying-in' research only professors (Aspromougos 2012) or existing teaching and research staff obtaining research only ARC Future Fellowships or similar intensive research funding. Despite an increase in the overall number of research only appointments across all levels of academic appointments from 2010 to 2012, the number is still relatively low and there are fewer Levels D and E research only appointments than early career researchers. The significance of this observation is the potential impact the small number of experienced researchers may have on the research culture of Educational AOUs. With a greater concentration of research only academics, it is more likely that AOUs will also exhibit more organisational and career indicators of a research active climate: greater research focus; more teaching and research academics involved in funded research projects; more internal seed funding; and, more intensive career development support for early career researchers. Remembering that the data in the current project only relates to those academics who contributed to the ERA submissions, more information is needed to make definitive comparisons between the research only pathways available to academics of various appointment types and levels in Education and non-Education AOUs and across different fields of research. These opportunities will also be shaped by regional location and placement within the university networks and the research resources at their disposal.

Another significant change in the data is the large increase in the number of 'other' academics contributing to the FoR Education ERA 2012 assessment exercise. Missing appointment data occurred for both ERA data sets for nearly all 13 universities, and because information were de-identified prior to submission it was not possible to form any firm conclusions about this group of academics contributing to Category 1 and 3 
outputs. However, given that the increase coincided with increases in the number of all appointment types and levels, some of these academics in the 'other' category would be honorary appointments. Certainly, an increase in the number of research active honorary appointments will help FoR Education maximise its potential ERA submissions. Follow up is needed to explore the exact nature of this group of researchers and, more importantly, to determine whether they are an under-utilised resource in our quest to strengthen the capacity of educational research.

\section{Institutional and geographical location of educational researchers}

The 13 datasets from both audits were also used to look for patterns according to institutional location. The datasets were examined in two ways: first, according to Australian University Groupings; and second, according to a set of geographic groupings.

Figure 4 shows that GO8 Universities contributed more than half of the total FoR Education submissions for each ERA exercise and that this proportion actually grew by $6 \%$. In the same period, the FoR Education submission by Regional and Innovative Universities was roughly stable but the proportion submitted from Other Universities decreased by $5 \%$. 


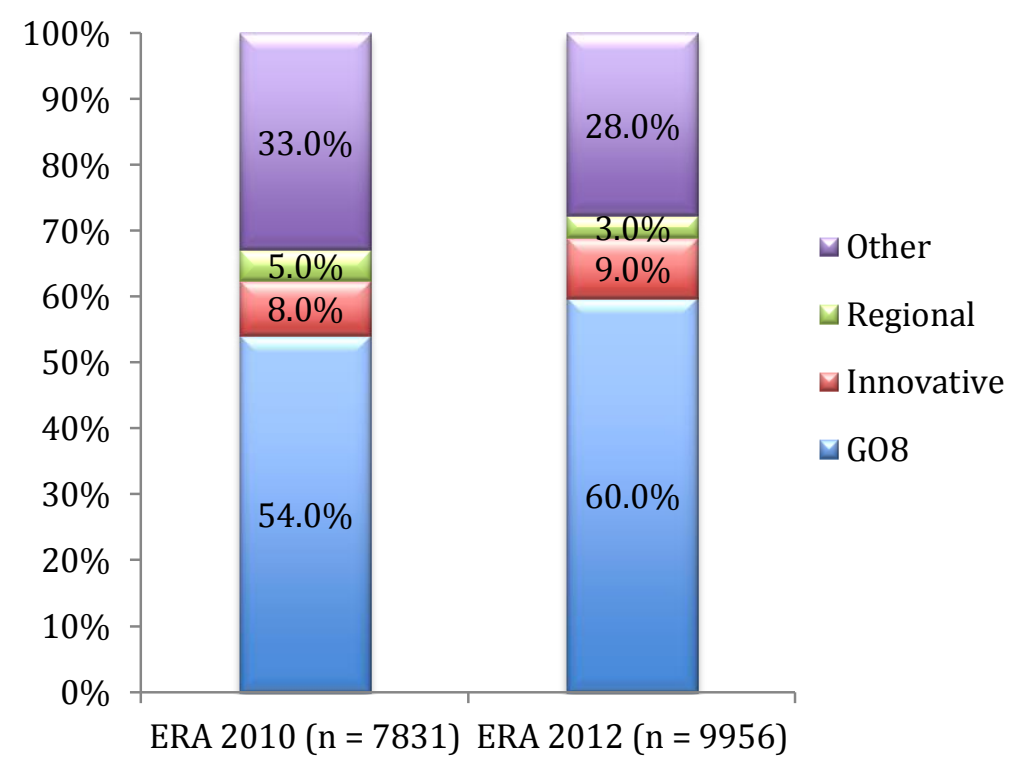

Fig. 4. Comparison of percentage share of FoR Education outputs submitted by 13 universities to ERA 2010 and 2012 according to Australian University Groupings

Figure 5 shows the percentage share of outputs by Category 1 and 3 academics for ERA 2010 and 2012, according to the three regional categories - Southeast, East and West/Northeast/Central - generated by the research team in response to concerns about anonymity and confidentiality of institutional data.

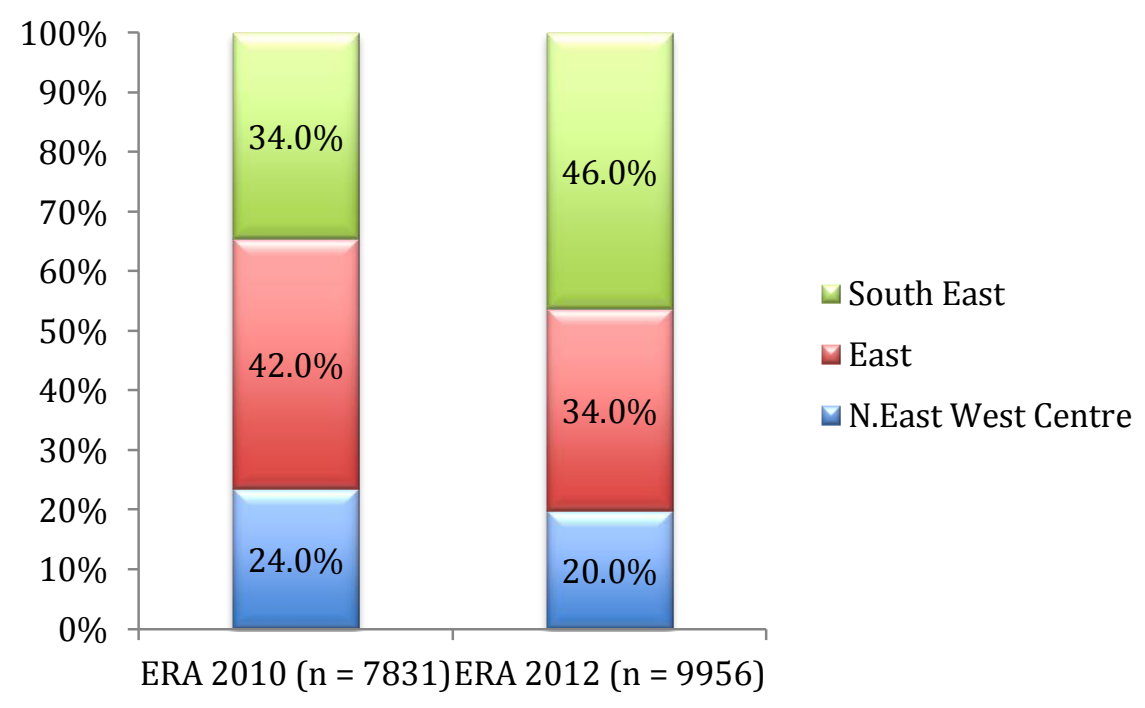

Figure 5. Percentage share of FoR Education outputs submitted by 13 universities to ERA 2010 and 2012 according to geographical region

Of the 13 usable data sets, three were located in the Southeast, five in the East, and five were located in the Northeast/West/Central regions of Australia. Figure 5 shows 
that the proportion of outputs submitted from the Eastern Universities decreased from 2010 to 2012 and increased by approximately the same amount from universities located in the Southeast.

The exact reasons for a shift in the share of outputs from one region to another are not possible to determine from output data alone. However, it may be attributed to the increase in the number of research only academic appointments in the Southeast universities. Figures 6 and 7 show the number of ERA 2010 and 2012 academics contributing to FoR Education according to their type of appointment for each of our three regional categories, respectively. A comparison of the two figures shows that teaching and research appointments remained fairly stable in the East and Southeast regional categories, but teaching and research appointments in the Northeast/West/Central region increased. At the same time, increases in research only and 'other' academics noted in Figures 1 and 2 were predominantly occurring in institutions located in the Southeast region. These data illustrate the variations that exist in the ecologies of Education AOUs across Australia. In particular, they highlight how research resources are spread unevenly and how quickly they can shift across universities and even geographical regions. Understanding the impact of such shifts is vitally important for a national approach to capacity building. 


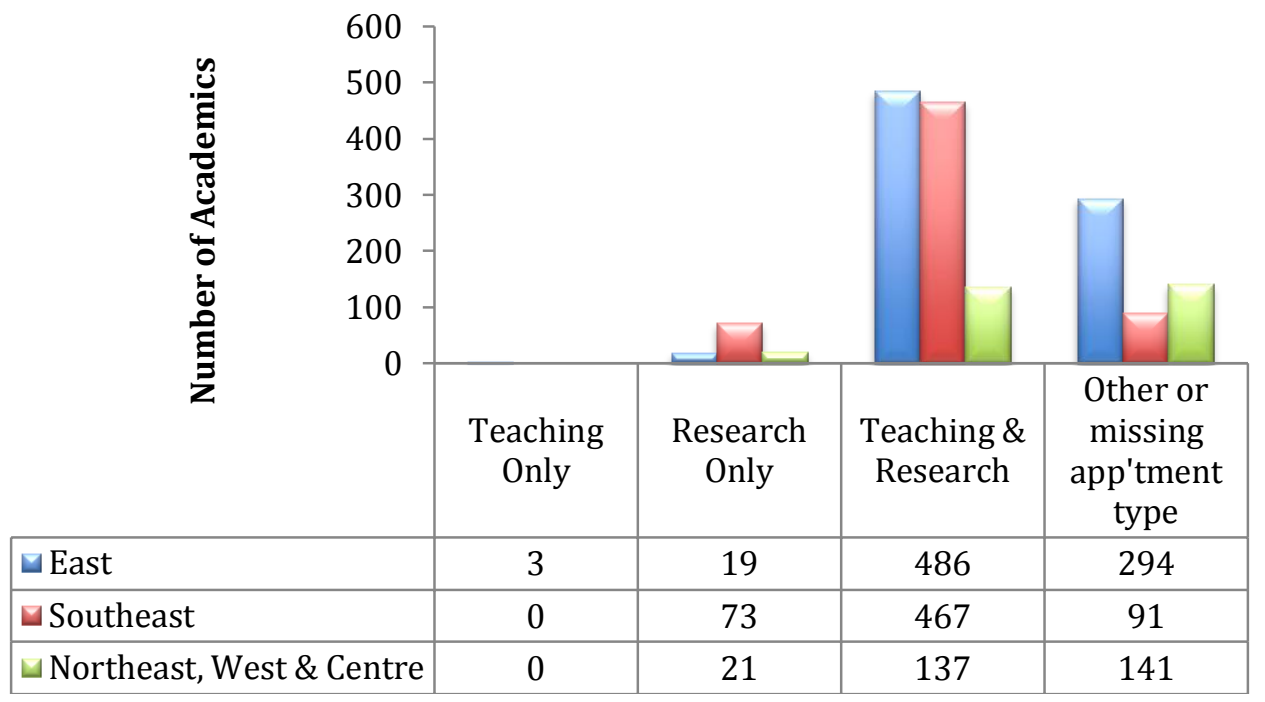

Fig. 6. Appointment type for ERA 2010 researchers contributing to the FoR Education submission

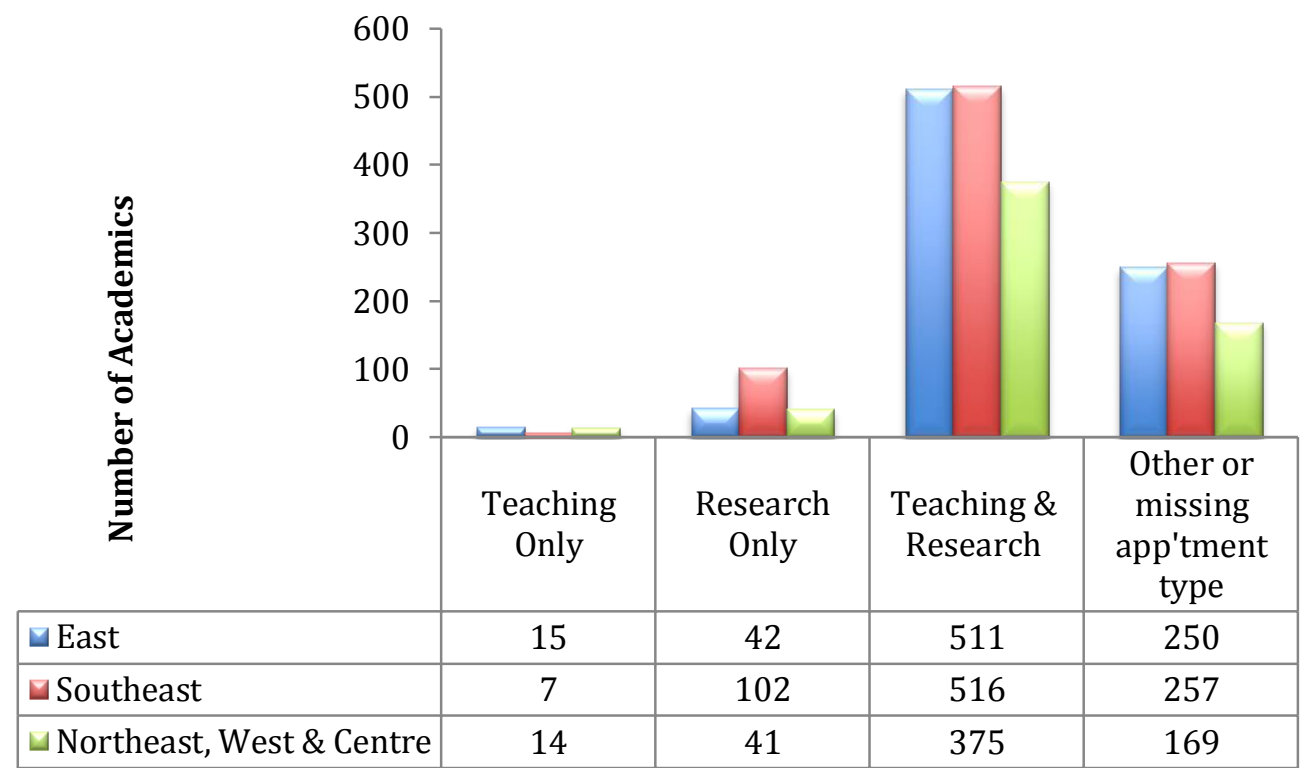

Fig. 7. Appointment type for ERA 2012 researchers contributing to the FoR Education output submission

\section{The nature of outputs produced by Educational Researchers}

ERA assesses academic outputs, not the purported quality of a researcher per se. In order to more fully understand the nature of the outputs submitted to FoR Education by researchers working in Education and non-Education AOUs, percentages for each type of output (book, book chapter, journal article, refereed conference paper and non-traditional outputs [NTRO]) were calculated. This allowed a closer examination 
of FoR Education Category 1 and 3 outputs to a level that has not previously been reported, including how and what researchers from non-Education AOUs contribute to FoR Education. Figures 8 and 9 report these data for ERA 2010 and 2012 data respectively.

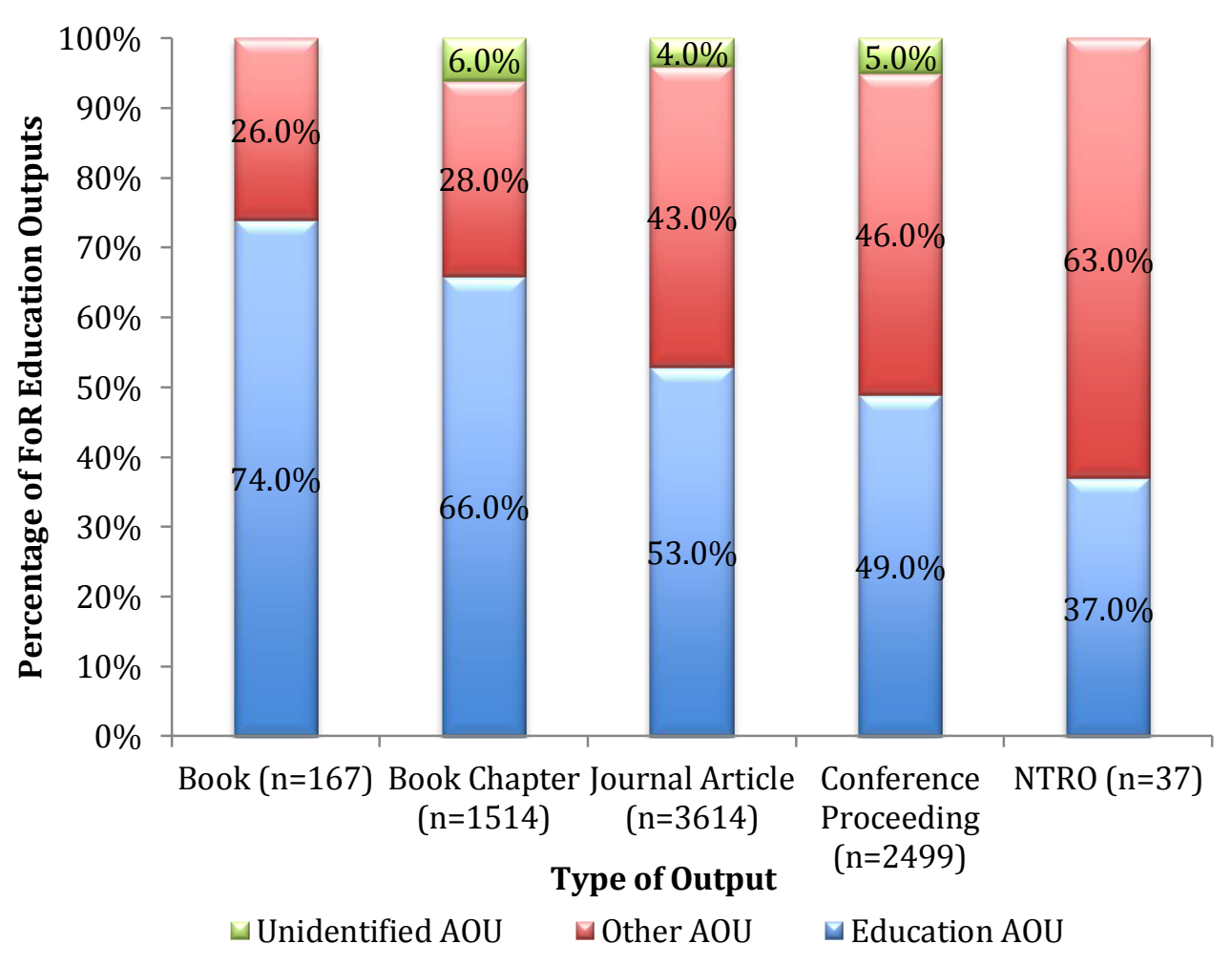

Fig. 8. Per cent of each type of output in FoR Education ERA 2010 submitted by Education AOUs and other AOUs 


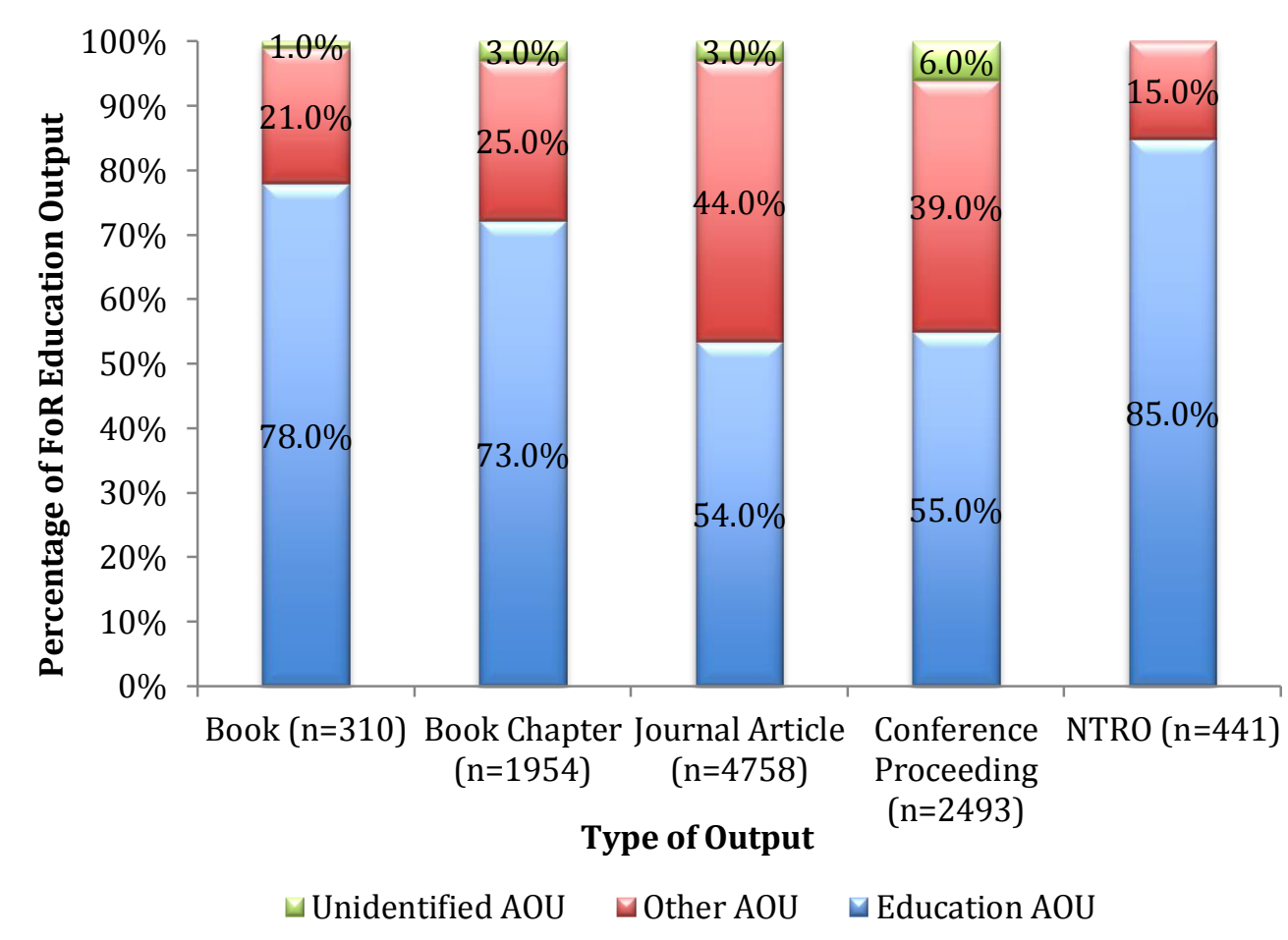

Fig. 9. Per cent of each type of output in FoR Education ERA 2012 submitted by Education AOUs and other AOUs

Figures 8 and 9 indicate that, in both audits, non-Education AOU researchers contributed a significant proportion of each type of FoR Education output, particularly conference papers, journal articles, and in the case of ERA 2010, the NTRO type. Comparison of the two data sets indicates that the proportion of all Category 3 output types for FoR Education decreased from ERA 2010 to ERA 2012 - down 7\% for conference papers, down 5\% for books, down 3\% for book chapters. The proportion of Category 3 NTROs significantly dropped 48 percentage points from approximately 63\% for ERA 2010 to just 15\% in ERA 2012.

These findings are consistent with those presented in Table 1 and with the earlier suggestion that the decision to submit a greater proportion of FoR Education coded outputs produced by researchers from Education AOUs was probably a deliberate one. Despite this, the proportion of Category 3 outputs to FoR Education is likely to remain significant in future research assessment exercises. The high proportion reflects the relevance of educational research to a diversity of non-Education AOUs across most universities. Future research capacity building strategies will need to 
acknowledge the significant role played by researchers working in non-Education AOUs who produce education-related research.

\section{FoRs and types of outputs produced in Education AOUs}

To more fully understand the extent and nature of outputs produced in Education AOUs, we examined the proportion of outputs according to assigned FoR code(s) and type (book, book chapter, journal article etc.).

Data revealed that Education AOUs in this study submitted outputs for assessment across all twenty-two 2-digit FoR codes in both assessment exercises. For ERA 2010, $81.9 \%$ of outputs were submitted to FoR Education, increasing to $84.4 \%$ for ERA 2012. In terms of our interest in exploring the potential for educational research capacity building this means that approximately $18 \%$ of outputs submitted by Education AOUs in ERA 2010 and 16\% in ERA 2012 contributed to fields of research outside of FoR 13 - Education. This has implications for how we understand the 'where' of educational research.

The remaining share of outputs produced by Education AOUs was distributed primarily to four other 2-digit codes: FoR 11 Medical and Health Sciences (3.1\% increasing to $3.5 \%$ ); FoR 16 Studies in Human Society (3.2\% decreasing to 2.3\%); FoR 20 Language, Communication Culture (2.5\% decreasing to 1.8\%); with the greatest increase occurring in FoR 17 Psychology and Cognitive Sciences, moving from $1.6 \%$ to $2.2 \%$ for ERA 2010 and ERA 2012 respectively.

The nature of outputs produced by researchers working in Education AOUs is further revealed when we examine the type of outputs submitted. Figure 10 shows the proportion of Category 1 and 2 outputs submitted to the two assessment exercises according to the type of output across all 2-digit FoRs. 


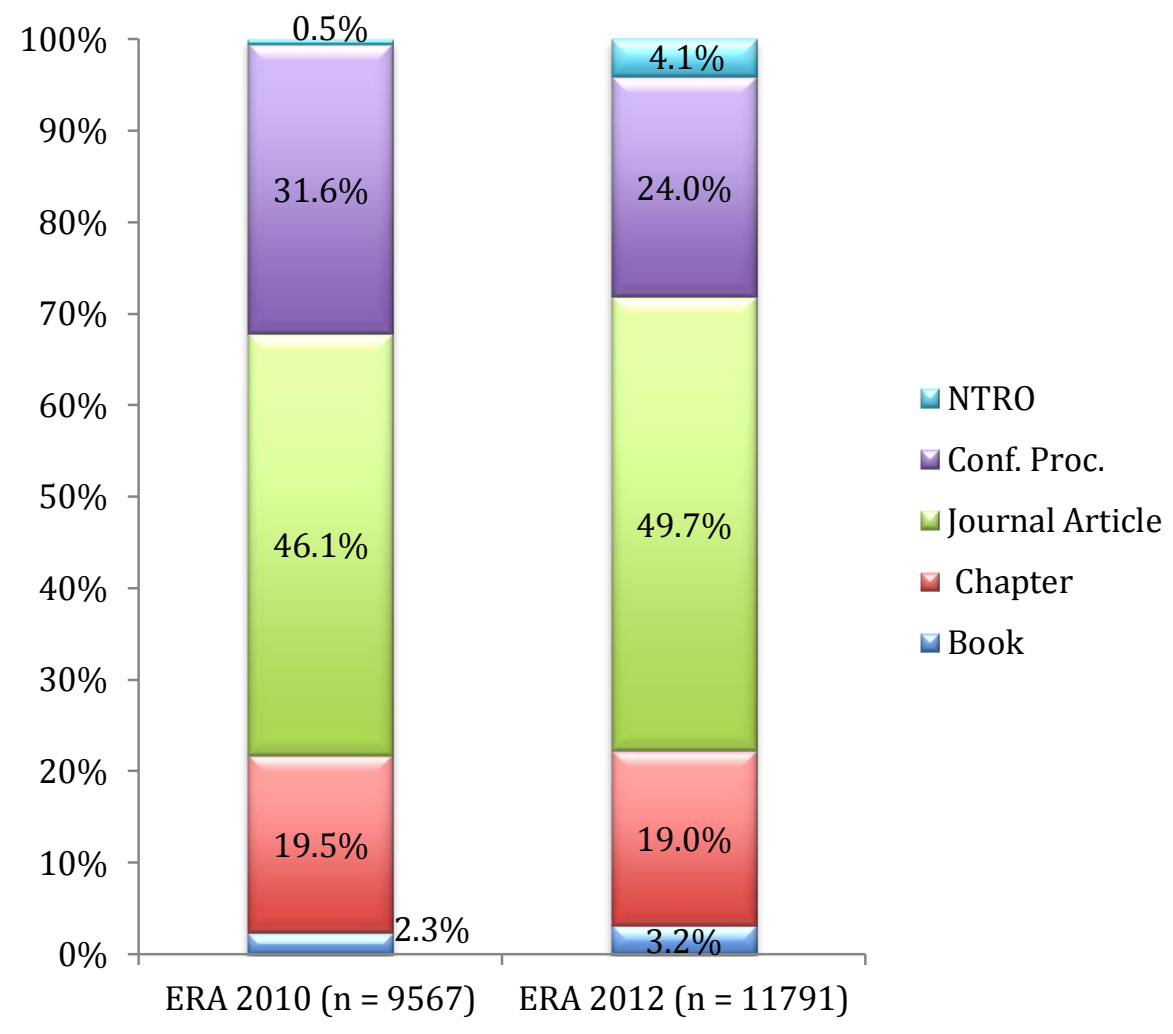

Fig. 10. ERA 2010 and 2012 outputs submitted by Education AOUs to all FoRs

Data reveals a $7.6 \%$ decrease in the share of conference papers and a $0.5 \%$ decrease in book chapters submitted to ERA 2012 compared to 2010. However, in the same period there was an increase in share of journal articles $(+3.6 \%)$, books $(+0.9 \%)$ and non-traditional outputs $(+3.6 \%)$. Notably, the increase in journal articles predominantly occurred in FoR Education coded journals.

These findings indicate a shift in the nature of research outputs produced by academics working in Education AOUs from ERA 2010 and 2012 - at least in terms of what was submitted for assessment. The majority of outputs submitted to ERA 2012 (produced in the assessment period 2005-2010) would already have been in the production pipeline prior to the ERA 2010 or 2012 guidelines being published. Therefore, it is unlikely that researchers working in Education AOUs had the opportunity to shift their research practices and/or the nature of their research outputs to the extent evident in the ERA 2012 data presented here. However, the shift in the 2012 data shows that Education AOUs have learnt to value certain outputs differently from pre-ERA times and have adopted strategic decision making practices to maximise research potential as far as audit practices are concerned. 


\section{FoR Education and educational research capacity building: Where to next?}

In this paper we have followed a line of thought from Hardy et al. (2012) that FoR Education is an 'administrative accountability' code constituted through statistical processes and administrative audit procedures (ABS 2012; ARC 2011). It cannot be conflated with educational research. That said, the findings from secondary analysis of ERA 2010 and 2012 data submitted by 13 participating universities for this study provides food for thought when contemplating educational research capacity building in the future.

We know that research audits measure, collect, collate and rank. On the one hand this may reflect the disciplinary diversity of educational research, its epistemological complexity and its alignment with research field codes: notably FoR 11 Medical and Health Sciences; FoR 16 Studies in Human Society; FoR 20 Language, Communication Culture; and FoR 17 Psychology and Cognitive Sciences. However, in 'coding out' (Hardy et al. 2011) these contributions, the research performance and research capacity building potential of some AOUs may be diluted. On the other hand, to understand research only according to FoR Education provides a narrow and instrumental understanding of an activity - educational research - which is never the code per se. Future educational research capacity building will need to acknowledge the nexus between knowledge work in and across the different academic disciplines associated with education as well as beyond the Academy in partnership with schools, workplaces and community learning agencies. We can use our knowledge of the audit systems to understand how we work across these epistemological boundaries, but calculable FoR fields alone will not create the synergies.

Performance based audits have been accused of controlling educational research, a line of argument we have also carried in this paper. However, the control of research through professional elites is not without foundation: internal governance processes including tenure, promotion, periodic reviews, evaluations of teaching, sponsorship on research grants and prestigious committees and peer review of publications are not the neutral and objective processes that the scholarly code of review would have us believe. For many, (Connell 2007; Hardy et al. 2011; Ozga et al. 2006; Rizvi 2009) 
the development of 'world standard' research is already controlled by elites and already constrained by a notion of international excellence that undermines diversity and equity. With increasing competition between universities, disciplines, AOUs and academics - for this is a primary goal of audit exercises - the task will be to create better capacity building structures that respond to diversity and equity and minimalize energy and funding directed to audit for audit's sake.

\section{Acknowledgement}

We acknowledge and thank Kerrie Legge and Merril Bouckley from the University of Sydney for their assistance in the collation of ERA data. 


\section{References}

Aspromourgos, T. (2012). The managerialist university: an economic interpretation. Australian Universities' Review, 54(2), 44-49, Viewed 24 February 2012 http://search.informit.com.au.ezproxy.cdu.edu.au/fullText; $\mathrm{dn}=201210598 ; \mathrm{res}=\mathrm{A}$ $\underline{\text { PAFT }}$

Australian Bureau of Statistics (2012). Australian and New Zealand Standard Research Classification (ANZSRC), viewed 10 March, 2013 at http://www.abs.gov.au/ausstats/abs@.nsf/Latestproducts/1297.0Main\%20Feature s52008? opendocument $\&$ tabname $=$ Summary $\&$ prodno $=1297.0 \&$ issue $=2008 \&$ num $=\&$ view $=$

Australian Council of Deans of Education [ACDE] (2009). Higher education workforce issues in the field of Education. Background briefing paper 7 for Julia Gillard, April 2009.

Australian Education Network (2012). University groupings, Viewed 26 October 2012 at http://www.australianuniversities.com.au/directory/australian-universitygroupings/

Australian Research Council (2009). ERA-SEER 2010 Technical Specifications. Viewed 9 October 2012 at http://www.arc.gov.au/era/era 2010/archive/key docs10.htm, Australian Research Council (2011). ERA 2010 National Report. Viewed 9 October 2012 at http://www.arc.gov.au/era/era 2010/outcomes 2010.htm

Bebbington, W. (2012) Deja vu all over again: what next for universities? Australian Universities' Review, 54(2) 73-77. Viewed 24 February 2013 at http://search.informit.com.au.ezproxy.cdu.edu.au/fullText; $\mathrm{dn}=201210603 ; \mathrm{res}=\mathrm{A}$ $\underline{\text { PAFT }}$

Besley, T. (ed) (2009). Assessing the Quality of Educational Research in Higher Education International Perspectives, Sense Publishers Rotterdam/Boston/Taipei.

Connell, R. (2007). Southern theory: the global dynamics of knowledge in social science, Cambridge: Polity.

Cooper, S., \& Poletti, A. (2011). The new ERA of journal ranking: the consequences of Australia's fraught encounter with 'quality'. Australian Universities' Review, 53(1), 57-65. Viewed 24 February 2013 at 
http://search.informit.com.au.ezproxy.cdu.edu.au/fullText; $\mathrm{dn}=201103844 ; \mathrm{res}=\mathrm{A}$ PAFT

Cummings, J. (2010). Renewing the Academic and Research Workforce in Education: Challenges and Opportunities, Report for the Australian Council of Deans of Education. Viewed 20 February 2013 at http://www.acde.edu.au/pages/images/ACDE\%20WORKFORCE\%20PAPER\%2 0SEPT\%202010.pdf

Furlong, J. (2011) Universities and the discipline of education: understanding the impact of the United Kingdom's Research Assessment Exercise, Power and Education 3(1), 18-30.

Gardner, J., \& Gallagher, T. (2007). Gauging the Deliverable? Educational Research in Northern Ireland, European Educational Research Journal, 6(1), 101-114.

Hardy, I., Heimans, S., \& Lingard, B. (2011). Journal rankings: positioning the field of educational research and educational academics, Power and Education, 3(1), 4-17.

Hicks, D. (2012). Performance-based university research funding systems, Research Policy, 41, 251-261.

Kwok, J. T. (2013). Impact of ERA research assessment on university behaviour and their staff. NTEU National Policy \& Research Unit. NTEU, South Melbourne.

Larkins, F. P. (2013a). 2012 ERA (Part 1) University Responses and Performances Compared with ERA 2010. LH Martin Institute, Carlton Victoria.

Larkins, F. P. (2013b). ERA 2012 (Part 2): Discipline Research Profile Changes 2010 to 2012. LH Martin Institute, Carlton Victoria.

Lawn, M., \& Furlong, J. (2007). The Social Organisation of Education Research in England, European Educational Research Journal, 6(1), 55-70.

Marginson, S. (2002). Towards a politics of the enterprise university, In Cooper, S., Hinkson, J. \& Sharp, G. (eds) (2002) Scholars and Entrepreneurs: the universities in crisis. Arena Publications Association North Carlton: 137-151.

Onancea, A. (2010). The BERA/UCET Review of the Impacts of RAE 2008 on Education Research in UK Higher Education Institutions, London: British Educational Research Association.

Ozga, J., Seddon, T., \& Popkewitz, T. (2006). Introduction: education research and policy - steering the knowledge-based economy, In Ozga, J., Seddon, T. and Popkewitz, T. (Eds.), World Yearbook of Education 2006: Education, Research 
and Policy: Steering the Knowledge-based economy. (pp. 1-14) Routledge: New York.

Rizvi, F. (2009). Internationalization and the assessment of research quality in education. In Besley, T. (Ed.), Assessing the quality of educational research in higher education international perspectives, (pp. 49-58) Sense Publishers Rotterdam/Boston/Taipei.

Ryan, S. (2012). Academic zombies: a failure of resistance or a means of survival? Australian Universities' Review, 54(2), 3-11. Viewed 24 February 2013 at http://search.informit.com.au.ezproxy.cdu.edu.au/fullText; $\mathrm{dn}=201210593 ; \mathrm{res}=\mathrm{A}$ PAFT

Thrift, N. J. (2005). Knowing capitalism. London: Sage Publications.

Jansen, H., \& Watts, M. F. (2011). The power of the code. Power and Education, 3(1), 52-63.

O'Neill, A., \& Speechley, B. (2011). Looking back into the future. Australian Universities' Review, 53(1), 94-99.

Rose, N. (1999). Powers of freedom: reframing political thought. Cambridge: Cambridge University Press. 